\title{
Risperidone Treatment after Transient Ischemia Induces Hypothermia and Provides Neuroprotection in the Gerbil Hippocampus by Decreasing Oxidative Stress
}

\author{
Go Eun Yang ${ }^{1,+}$, Hyun-Jin Tae ${ }^{2,+}$, Tae-Kyeong Lee ${ }^{3}$, Young Eun Park ${ }^{3}$, Jeong Hwi Cho ${ }^{2}$, \\ Dae Won Kim ${ }^{4}$, Joon Ha Park ${ }^{5}$, Ji Hyeon Ahn ${ }^{6}$, Sungwoo Ryoo ${ }^{7}$, Young-Myeong Kim ${ }^{8}$, \\ Myoung Cheol Shin ${ }^{9}$, Jun Hwi Cho ${ }^{9}$, Choong-Hyun Lee ${ }^{10}$, In Koo Hwang ${ }^{11} \mathbb{D}$, Hui Jin ${ }^{12}$, \\ Moo-Ho Won ${ }^{3, *}$ (D) and Jae-Chul Lee ${ }^{3, *}$
}

1 Department of Radiology, Kangwon National University Hospital, Chuncheon, Gangwon 24289, Korea; yangke@kangwon.ac.kr

2 Bio-Safety Research Institute, College of Veterinary Medicine, Jeonbuk National University, Iksan, Jeollabuk 54596, Korea; anatotae@gmail.com (H.-J.T.); uribugi@naver.com (J.H.C.)

3 Department of Neurobiology, School of Medicine, Kangwon National University, Chuncheon, Gangwon 24341, Korea; xorud312@naver.com (T.-K.L.); taeparo@naver.com (Y.E.P.)

4 Department of Biochemistry and Molecular Biology, and Research Institute of Oral Sciences, College of Dentistry, Gangnung-Wonju National University, Gangneung, Gangwon 25457, Korea; kimdw@gwnu.ac.kr

5 Department of Anatomy, College of Korean Medicine, Dongguk University, Gyeongju, Gyeongbuk 38066, Korea; jh-park@kangwon.ac.kr

6 Department of Biomedical Science and Research Institute for Bioscience and Biotechnology, Hallym University, Chuncheon, Gangwon 24252, Korea; jh-ahn@hallym.ac.kr

7 Department of Biological Sciences, College of Natural Sciences, Kangwon National University, Chuncheon, Gangwon 24341, Korea; ryoosw08@kangwon.ac.kr

8 Department of Molecular and Cellular Biochemistry, School of Medicine, Kangwon National University, Chuncheon, Gangwon 24341, Korea; ymkim@kangwon.ac.kr

9 Department of Emergency Medicine, School of Medicine, Kangwon National University, Chuncheon, Gangwon 24341, Korea; dr10126@naver.com (M.C.S.); cjhemd@kangwon.ac.kr (J.H.C.)

10 Department of Pharmacy, College of Pharmacy, Dankook University, Cheonan, Chungcheongnam 31116, Korea; anaphy@dankook.ac.kr

11 Department of Anatomy and Cell Biology, College of Veterinary Medicine, and Research Institute for Veterinary Science, Seoul National University, Seoul 08826, Korea; vetmed2@snu.ac.kr

12 Center for Nutraceutical and Pharmaceutical Materials, Myongji University, Yongin, Gyeonggi 17058, Korea; jimmykim83@mju.ac.kr

* Correspondence: mhwon@kangwon.ac.kr (M.-H.W.); anajclee@kangwon.ac.kr (J.-C.L.); Tel.: +82-33-250-8891 (M.-H.W.); +82-33-250-8892 (J.-C.L.); Fax: +82-33-256-1614 (M.-H.W. \& J.-C.L.)

+ These authors contributed equally to this work.

Received: 23 July 2019; Accepted: 15 September 2019; Published: 18 September 2019

Abstract: Compelling evidence from preclinical and clinical studies has shown that mild hypothermia is neuroprotective against ischemic stroke. We investigated the neuroprotective effect of post-risperidone (RIS) treatment against transient ischemic injury and its mechanisms in the gerbil brain. Transient ischemia (TI) was induced in the telencephalon by bilateral common carotid artery occlusion (BCCAO) for 5 min under normothermic condition $\left(37 \pm 0.2^{\circ} \mathrm{C}\right)$. Treatment of RIS induced hypothermia until $12 \mathrm{~h}$ after TI in the TI-induced animals under uncontrolled body temperature (UBT) compared to that under controlled body temperature (CBT) (about $37^{\circ} \mathrm{C}$ ). Neuroprotective effect was statistically significant when we used 5 and $10 \mathrm{mg} / \mathrm{kg}$ doses $(p<0.05$, respectively). In the RIS-treated TI group, many CA1 pyramidal neurons of the hippocampus survived under UBT compared to those under CBT. In this group under UBT, post-treatment with RIS to TI-induced 
animals markedly attenuated the activation of glial cells, an increase of oxidative stress markers [dihydroethidium, 8-hydroxy-2' -deoxyguanosine (8-OHdG), and 4-Hydroxynonenal (4-HNE)], and a decrease of superoxide dismutase 2 (SOD2) in their CA1 pyramidal neurons. Furthermore, RIS-induced hypothermia was significantly interrupted by NBOH-2C-CN hydrochloride (a selective $5-\mathrm{HT}_{2 \mathrm{~A}}$ receptor agonist), but not bromocriptine mesylate (a $\mathrm{D}_{2}$ receptor agonist). Our findings indicate that RIS-induced hypothermia can effectively protect neuronal cell death from TI injury through attenuation of glial activation and maintenance of antioxidants, showing that $5-\mathrm{HT}_{2 \mathrm{~A}}$ receptor is involved in RIS-induced hypothermia. Therefore, RIS could be introduced to reduce body temperature rapidly and might be applied to patients for hypothermic therapy following ischemic stroke.

Keywords: ischemia/reperfusion; delayed neuronal death; antipsychotic drug; post-treatment; thermoregulation; $5-\mathrm{HT}_{2 \mathrm{~A}}$ antagonist

\section{Introduction}

Neuroprotective compounds provide protection in models of ischemic stroke; however, none have shown efficacy in clinical trials [1]. Body temperature influences outcome of ischemic stroke [2,3], and hypothermia is one of the most promising neuroprotective therapies, as assessed by the Stroke Therapy Academic Industry Roundtable Criteria [4]. Although the precise mechanism of hypothermic neuroprotection in ischemic stroke is not known, hypothermia may act upon multiple pathways to ultimately prevent neuronal death [5]. It has been attempted to find drugs, including atypical antipsychotic agents with hypothermic effects [6,7], to treat ischemic stroke. The drugs reduce temperature instantly when a patient is picked up by emergency personnel, which are already approved for patient treatment and used anywhere, independent of sophisticated cooling equipment, and may prolong therapeutic time window for other treatments. Thus, atypical antipsychotic agent-induced hypothermia may help to overcome brain injury following ischemic stroke. For several decades, risperidone (RIS) has been widely used for treatment of schizophrenia as a selective monoaminergic antagonist with high-affinity for serotonin type $2\left(5-\mathrm{HT}_{2 \mathrm{~A}}\right)$ receptor and dopamine type $2\left(\mathrm{D}_{2}\right)$ receptor in the limbic system [8,9]. In addition, RIS-induced hypothermia has been reported [10,11]. It remains possible that RIS contains neuroprotection against ischemic stroke via hypothermia. Thus, this study determined whether neuroprotective effect of RIS is hypothermia as a post-conditioning stimulus for inducing ischemic tolerance and elucidated RIS-induced hypothermic mechanisms. For this purpose, we intended (1) to compare effects of RIS on transient ischemic damage between ischemic animals without regulating body temperature and with maintaining body temperature; (2) to study effects of RIS against ischemia-induced oxidative stress; and (3) to investigate roles of central 5- $\mathrm{HT}_{2 \mathrm{~A}}$ and $\mathrm{D}_{2}$ receptors in body temperature regulation in RIS-treated animals.

\section{Results}

\subsection{Effects of RIS Against TI Injury Under Uncontrolled Body Temperature (UBT)}

\subsubsection{Body Temperature under UBT Condition after TI}

Under UBT condition, an abrupt elevation of body temperature was seen in the TI + vehicle group after $\mathrm{TI}$, and the maximum temperature $\left(39 \pm 0.5^{\circ} \mathrm{C}\right)$ was at $1 \mathrm{~h}$ after $\mathrm{TI}$; thereafter, body temperature was gradually decreased (Figure 1A). Unlike the TI + vehicle group, in the TI + RIS groups under UBT condition, body temperature was decreased, as shown in Figure 1A. RIS produced a dose-dependent decrease in body temperature, and the effect was statistically significant in 5 and $10 \mathrm{mg} / \mathrm{kg}$ doses $(p<0.05$, respectively) in comparison to the TI + vehicle group (Figure $1 \mathrm{~A})$. In particular, the time 
course shows a rapid onset in the highest dose, with a maximal effect between 1 and $2 \mathrm{~h}$ and duration of $6 \mathrm{~h}$. A similar pattern, although less pronounced, was seen with the two lower doses.

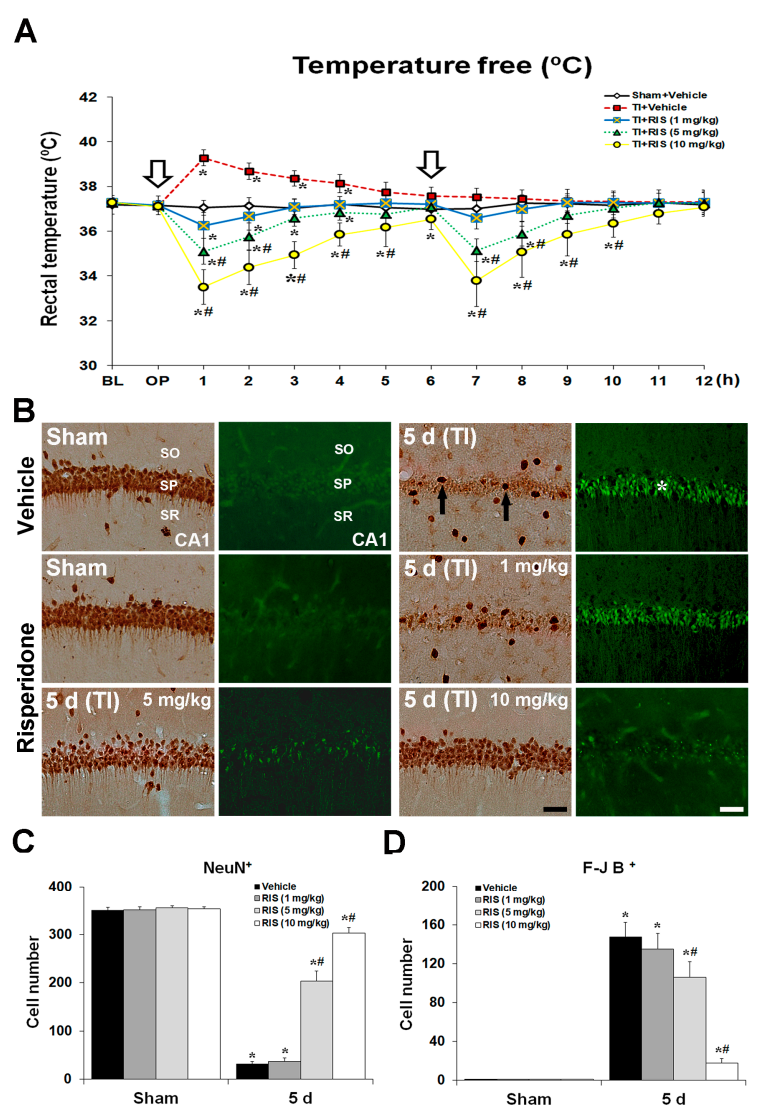

Figure 1. Effects of risperidone (RIS) against transient ischemia (TI) injury under uncontrolled body temperature (UBT) condition. (A) Changes in body temperature under UBT condition for $12 \mathrm{~h}$ after TI. Body temperature is significantly low in the TI $+10 \mathrm{mg} / \mathrm{kg}$ RIS group compared to the TI + vehicle group. White arrows indicate times of RIS treatment. The bars indicate the means \pm SEM, $n=7 /$ group, two-way analysis of variance (ANOVA) with a post-hoc Bonferroni's multiple comparison test $\left({ }^{*} p<0.05\right.$ vs. sham + vehicle group; \# $p<0.05$ vs. TI + vehicle group). (B) Effects of RIS on NeuN ${ }^{+}$and F-J B B $^{+}$ cells in the CA1 under UBT condition after TI. In the sham + vehicle group, CA1 pyramidal neurons are well stained with NeuN; however, no F-J B ${ }^{+}$CA1 pyramidal cells are found. In the TI + vehicle group, a few $\mathrm{NeuN}^{+}$cells (arrows) are shown in the stratum pyramidale (SP) 5 days after TI; however, the distribution of $\mathrm{NeuN}^{+}$cells in the TI + RIS group is similar to that in the sham + vehicle group. In the $\mathrm{TI}+$ vehicle group, many F-J B $\mathrm{B}^{+}$cells (asterisks) are detected in the SP 5 days after TI, and many F-J B ${ }^{+}$CA1 pyramidal cells (asterisks) are detected; however, in the TI + RIS group, RIS produces a dose-dependent increase in the number of $\mathrm{NeuN}^{+} \mathrm{CA} 1$ pyramidal neurons, and a dose-dependent decrease in the number of F-J B ${ }^{+}$CA1 pyramidal cells 5 days after TI. CA1, cornu ammonis 1; CA3, cornu ammonis 3; DG, dentate gyrus; $\mathrm{SO}$, stratum oriens; SR, stratum radiatum. Scale bar $=50 \mu \mathrm{m}$. Note histograms of quantitative analyses of $\mathrm{NeuN}^{+}$and F-J B ${ }^{+}$cells in all the groups, as shown (C) and (D). The bars indicate the means \pm SEM, $n=7$ /group, two-way analysis of variance (ANOVA) with a post-hoc Bonferroni's multiple comparison test ( ${ }^{*} p<0.05$ vs. sham + vehicle group; $\# p<0.05$ vs. $\mathrm{TI}+$ vehicle group).

\subsubsection{Neuronal Nuclear Antigen (NeuN) Positive $\left(^{+}\right)$and Fluoro-Jade B (F-J B $)^{+}$Neurons}

The protection afforded by RIS against TI-induced neuronal death in the CA1 was assessed under UBT condition using NeuN immunohistochemistry and F-J B histofluorescence staining (Figure 1B-D). In the sham + vehicle group, pyramidal cells or neurons in the CA1, which are called CA1 pyramidal 
neurons, were well stained with NeuN; however, no F-J B ${ }^{+}$CA1 pyramidal cells were found. At 5 days after $\mathrm{TI}, \mathrm{NeuN}^{+} \mathrm{CA} 1$ pyramidal neurons were markedly decreased, and many F-J B ${ }^{+}$CA1 pyramidal cells were detected. In the sham + RIS group, CA1 pyramidal neurons were also well stained with NeuN, and F-J B ${ }^{+}$cells were not observed. In the TI + RIS group, RIS produced a dose-dependent increase in the number of $\mathrm{NeuN}^{+} \mathrm{CA} 1$ pyramidal neurons, and a dose-dependent decrease in the number of F-J B ${ }^{+}$CA1 pyramidal cells 5 days after TI: The results were statistically significant for 5 and $10 \mathrm{mg} / \mathrm{kg}$ doses $(p<0.05$, respectively) in comparison with the TI + vehicle group. Based on these findings, we found better results in the TI + RIS $(10 \mathrm{mg} / \mathrm{kg})$ group than those in the TI + RIS $(5 \mathrm{mg} / \mathrm{kg})$ group, and examined the underlying hypothermic mechanism related to the neuroprotective effect of RIS against TI damage in the TI + RIS $(10 \mathrm{mg} / \mathrm{kg})$ group.

2.1.3. Glial Fibrillary Acidic Protein (GFAP) ${ }^{+}$and Ionized Calcium-Binding Adapter Molecule 1 $(\text { Iba- } 1)^{+}$Cells

Changes in $\mathrm{GFAP}^{+}$and Iba- $1^{+}$cells in the CA1 were examined at 1 day and 5 days after TI (Figure 2A-D). $\mathrm{GFAP}^{+}$and Iba- $1^{+}$cells, as a resting for, were distributed throughout all layers of the CA1 of the sham + vehicle group. In the TI + vehicle group, immunoreactivity of the GFAP and Iba-1 was slightly increased 1 day after TI compared to that in the sham + vehicle group. Five days after TI, the immunoreactivity was significantly increased, and most of the GFAP ${ }^{+}$and $\mathrm{Iba}-1^{+}$cells were hypertrophied in the CA1. In the sham + RIS group, the immunoreactivity and morphology of $\mathrm{GFAP}^{+}$and Iba- $1^{+}$cells were similar to that in the sham + vehicle group. In the TI + RIS group at 1 day after $\mathrm{TI}$, the immunoreactivity and morphology of $\mathrm{GFAP}^{+}$and $\mathrm{Iba}-\mathrm{1}^{+}$cells were not significantly changed compared to the sham + vehicle group. However, 5 days after TI, these immunoreactivity in the TI + RIS group was significantly lower than that in the TI + vehicle group.

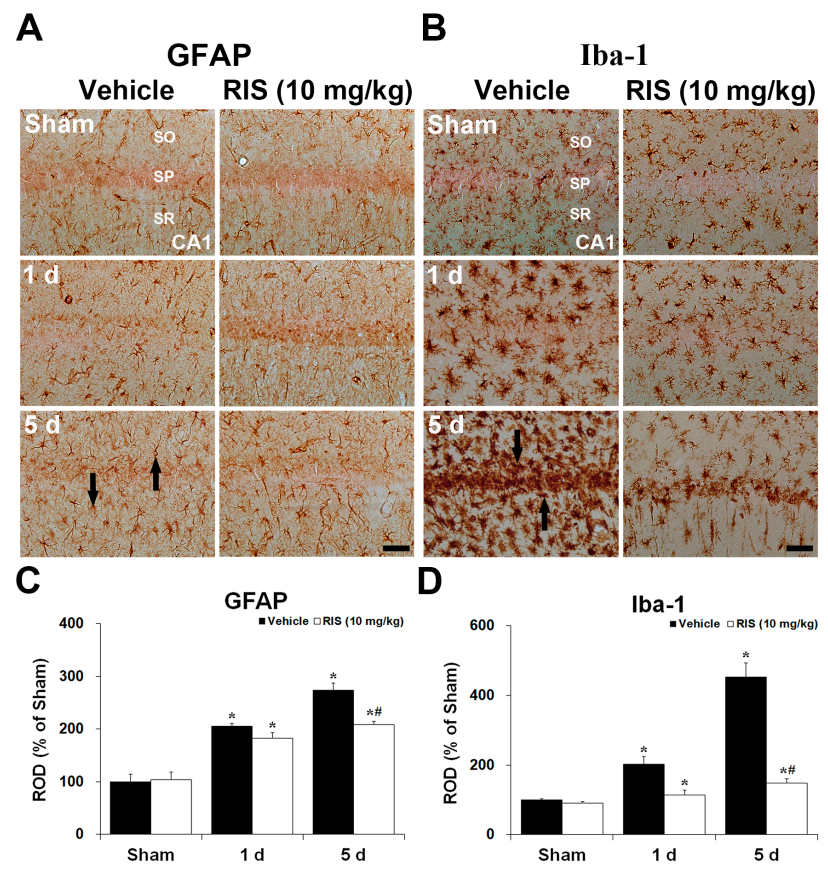

Figure 2. Effects of RIS on GFAP ${ }^{+}$astrocytes (A) and Iba- $1^{+}$microglia (B) in the CA1 after TI under UBT condition. GFAP ${ }^{+}$astrocytes (arrows in (A)) and Iba- $1^{+}$microglia (arrows in (B)) are markedly increased in the TI + vehicle group 5 days after TI; however, their immunoreactivity in the TI + RIS group is significantly lower than that in the TI + vehicle group. SO, stratum oriens; SP, stratum pyramidale; SR, stratum radiatum. Scale bar $=50 \mu \mathrm{m}$. Quantitative analyses of $\mathrm{GFAP}^{+}(\mathrm{C})$ and $\mathrm{Iba}-1^{+}$ cells (D). The bars indicate the means \pm SEM, $n=7$ /group, two-way analysis of variance (ANOVA) with a post-hoc Bonferroni's multiple comparison test ${ }^{*} p<0.05$ vs. sham + vehicle group; \# $p<0.05$ vs. TI + vehicle group). 


\subsection{Abolishment of RIS-Mediated Neuroprotection under Controlled Body Temperature (CBT)}

\subsubsection{Body Temperature under CBT Condition after TI}

After the onset of $\mathrm{TI}$, body temperature was maintained within normothermic range $\left(37.0-37.3^{\circ} \mathrm{C}\right)$ with a feedback-regulated heating pad for $12 \mathrm{~h}$ (Figure 3A). An abrupt elevation of body temperature was seen in the $\mathrm{TI}+$ vehicle group at $1 \mathrm{~h}$ after TI under CBT condition: The temperature was intensely increased (approximately $39.1 \pm 0.5^{\circ} \mathrm{C}$ ). Thereafter, body temperature was gradually decreased. However, under CBT condition, the degree of hypothermia induced by 5 and $10 \mathrm{mg} / \mathrm{kg}$ RIS injection was higher, respectively, than that under UBT condition, showing that body temperature was 36.8 and $36.1^{\circ} \mathrm{C}$, respectively, at $1 \mathrm{~h}$ after the first RIS treatment, and 36.6 and $36.1^{\circ} \mathrm{C}$, respectively, after the second injection.

\subsubsection{NeuN ${ }^{+}$Neurons, F-J B ${ }^{+}$Cells, GFAP ${ }^{+}$Astrocytes, and Iba- $1^{+}$Microglia}

Effects of CBT on RIS-mediated neuroprotection are shown in Figure 3B,C. In the sham + RIS group under $\mathrm{CBT}$, the distribution of $\mathrm{NeuN}^{+} \mathrm{CA} 1$ pyramidal neurons was similar to that in the sham + vehicle group. In the TI + RIS group under CBT, NeuN ${ }^{+}$CA1 pyramidal neurons were significantly decreased 5 days after TI. In addition, many F-J $\mathrm{B}^{+} \mathrm{CA} 1$ pyramidal cells were shown 5 days after TI under $\mathrm{CBT}$ condition. Changes of $\mathrm{GFAP}^{+}$and Iba- $1^{+}$cells under $\mathrm{CBT}$ condition were examined in the CA1 5 days after TI (Figure 3B,D). In the sham + RIS group under CBT, the immunoreactivity and morphology of GFAP ${ }^{+}$and Iba- $1^{+}$cells were not significantly different from those of the sham + vehicle group. In the TI + RIS group under CBT, GFAP and Iba-1 immunoreactivity 5 days after TI was significantly increased in the CA1, like the TI + vehicle group under UBT condition. 
A

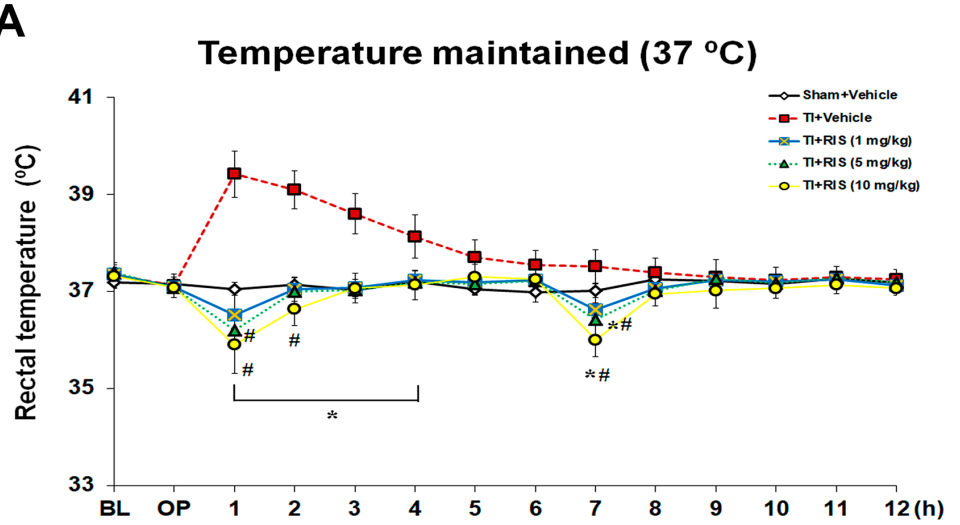

B
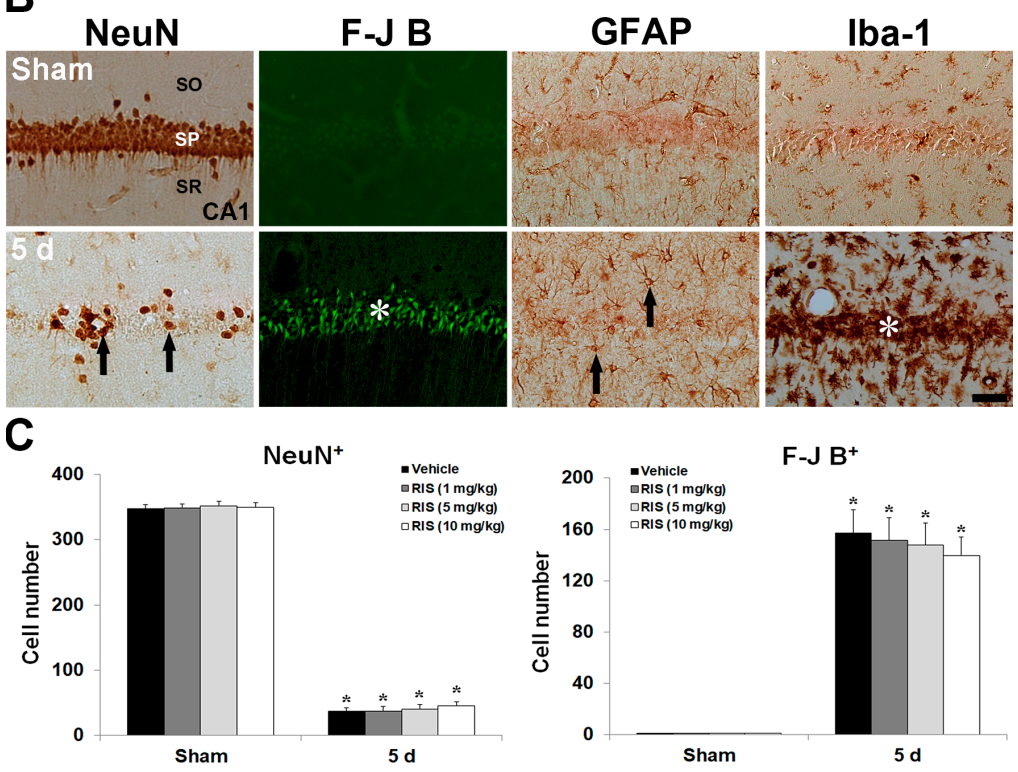

D
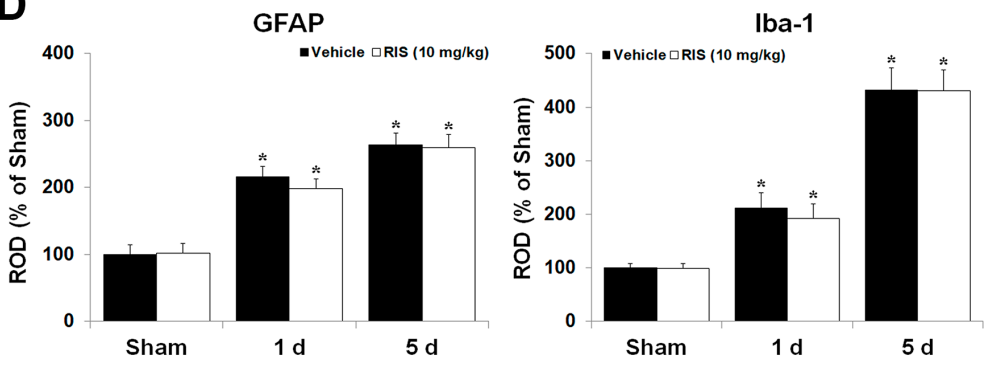

Figure 3. Effects of RIS against TI injury under controlled body temperature (CBT) condition. (A) Changes in body temperature under CBT condition for $12 \mathrm{~h}$ after TI. Body temperature is slightly low in the TI $+10 \mathrm{mg} / \mathrm{kg}$ RIS group compared to the TI $+5 \mathrm{mg} / \mathrm{kg}$ RIS group. White arrows indicate times of RIS treatment. The bars indicate the means \pm SEM, $n=7 /$ group, two-way analysis of variance (ANOVA) with a post-hoc Bonferroni's multiple comparison test ( ${ }^{*} p<0.05$ vs. sham + vehicle group; $\# p<0.05$ vs. TI + vehicle group). (B) Effect of RIS $\left(10 \mathrm{mg} / \mathrm{kg}\right.$ ) on NeuN ${ }^{+}, \mathrm{F}-\mathrm{J} \mathrm{B}^{+}, \mathrm{GFAP}^{+}$, and Iba- $1^{+}$ cells in the CA1 under CBT after TI 5 days after TI. In the TI + RIS group, a few $\mathrm{NeuN}^{+}$neurons (arrows) and many F-J B ${ }^{+}$cells (asterisks) are shown in the stratum pyramidale (SP) at 5 days after TI. GFAP ${ }^{+}$astrocytes (arrows) and Iba- $1^{+}$microglia (asterisks) are markedly increased in the TI + RIS group under CBT 5 days after TI. SO, stratum oriens; SP, stratum pyramidale; SR, stratum radiatum. Scale bar $=50 \mu \mathrm{m}$. Quantitative analyses of $\mathrm{NeuN}^{+}$and F-J B ${ }^{+}$cells $(\mathrm{C})$, and $\mathrm{GFAP}^{+}$and $\mathrm{Iba}-1^{+}$cells (D). The bars indicate the means \pm SEM, $n=7 /$ group, two-way analysis of variance (ANOVA) with a post-hoc Bonferroni's multiple comparison test $\left({ }^{*} p<0.05 \mathrm{vs}\right.$. sham + vehicle group $)$. 


\subsection{Effects of RIS Against TI-Induced Oxidative Stress under UBT and CBT Conditions}

\subsubsection{Superoxide Anion Production}

To analyze the potential role of superoxide anion in RIS-mediated neuroprotection against TI injury, the production of superoxide anion in the CA1 pyramidal neurons was determined using DHE reactivity after TI (Figure $4 \mathrm{~A}, \mathrm{~B}$ ). DHE reactivity was similar in all sham groups. Under UBT condition, superoxide anion was intensely induced in CA1 pyramidal neurons 1 day after TI; however, the reactivity was significantly decreased in the TI + RIS group. At this time, under CBT condition, superoxide anion production in the TI + RIS group was similar to that in the TI + vehicle group under UBT condition. Five days after TI, DHE reactivity in CA1 pyramidal neurons was hardly shown in all groups, because CA1 pyramidal neurons were killed in the TI + vehicle and TI + RIS groups under CBT condition, and CA1 pyramidal cells in the TI + RIS under UBT condition survived and did not product superoxide anion.

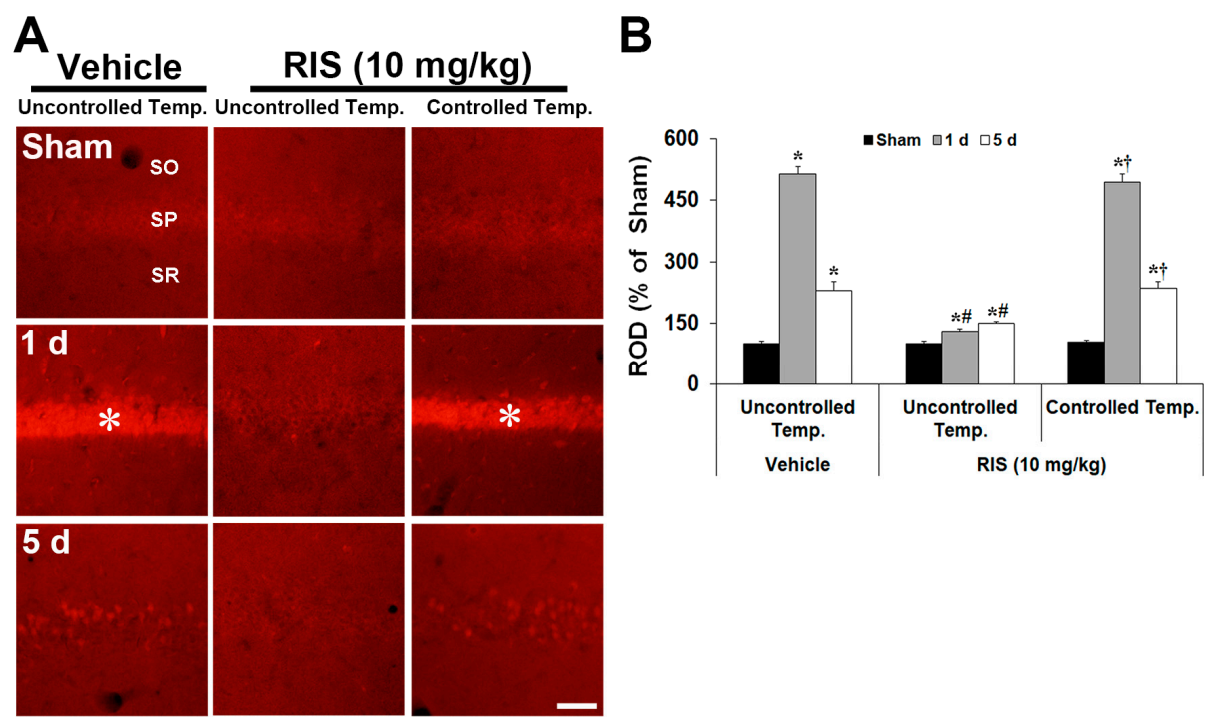

Figure 4. Effects of RIS on superoxide anion production after TI under UBT and CBT conditions. (A) Changes of DHE immunofluorescence in the CA1 after TI under UBT and CBT conditions. DHE immunofluorescence is significantly increased in CA1 pyramidal neurons of the stratum pyramidale (SP, asterisks) in the TI + vehicle group under UBT and TI + RIS group under CBT at 1 day after TI; however, DHE immunofluorescence is not significantly increased in the SP of the TI + RIS group under UBT condition. SO, stratum oriens; SR, stratum radiatum. Scale bar $=50 \mu \mathrm{m}$. (B) Note analyses of DHE immunofluorescence in the SP. A ratio of the ROD is calibrated as \%, with the sham + vehicle group designated as $100 \%$. The bars indicate the means \pm SEM, $n=7 /$ group, two-way analysis of variance (ANOVA) with a post-hoc Bonferroni's multiple comparison test ${ }^{*} p<0.05 \mathrm{vs}$. sham $+\mathrm{TI}+$ vehicle group under UBT condition; \# $p<0.05$ vs. TI + vehicle group under UBT condition; $\uparrow p<0.05$ vs. TI + RIS group under UBT condition.).

\subsubsection{8-Hydroxy-2'-deoxyguanosine (8-OHdG) and 4-hydroxy-2-nonenal (4-HNE) Immunoreactivity}

Changes in 8-OHdG (oxidative DNA damage) and 4-HNE (lipid peroxidation) in the CA1 were examined at 1 day and 5 days after TI (Figure 5A-D). Very weak 8-OHdG and 4-HNE immunoreactivity was detected in CA1 pyramidal neurons in all sham groups. At 1 day after TI, in the TI + vehicle group under UBT, immunoreactivity of the 8-OHdG and 4-HNE in CA1 pyramidal neurons was dramatically increased. At this point in time, these immunoreactivity in the TI + RIS group under UBT was slightly increased; however, in the TI + RIS group under CBT, immunoreactivity of the 8-OHdG and 4-HNE was similar to that in the TI + vehicle group under UBT condition. Five days after TI, immunoreactivity of the 8-OHdG and 4-HNE in CA1 pyramidal neurons of the TI + vehicle groups 
disappeared due to death of CA1 pyramidal neurons. At this point in time, in the TI + RIS group under UBT, the immunoreactivity in CA1 pyramidal neurons was similar to that at 1 day after TI, and 8-OHdG and 4-HNE immunoreactivity of the TI + RIS under CBT was hardly shown because CA1 pyramidal neurons were killed under CBT condition. In the TI + vehicle group under UBT, 8-OHdG immunoreactivity was significantly increased in CA1 pyramidal neurons 1 day after TI, and, at 5 days after TI, 8-OHdG immunoreactivity was hardly shown due to loss of CA1 pyramidal neurons.

A

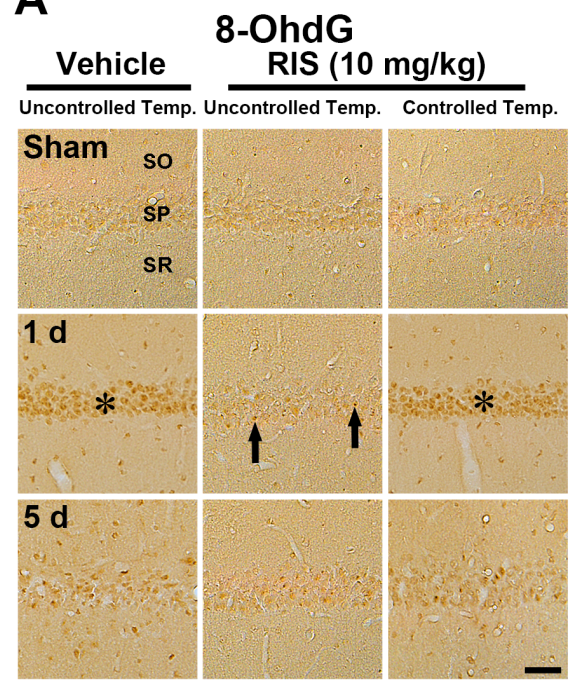

C

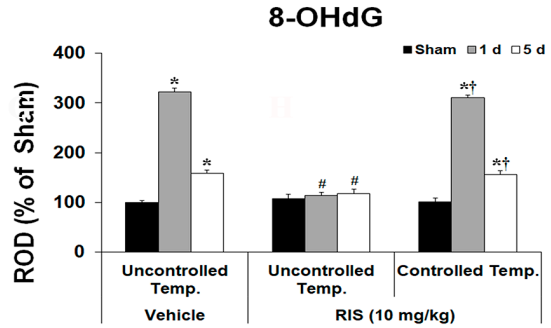

B

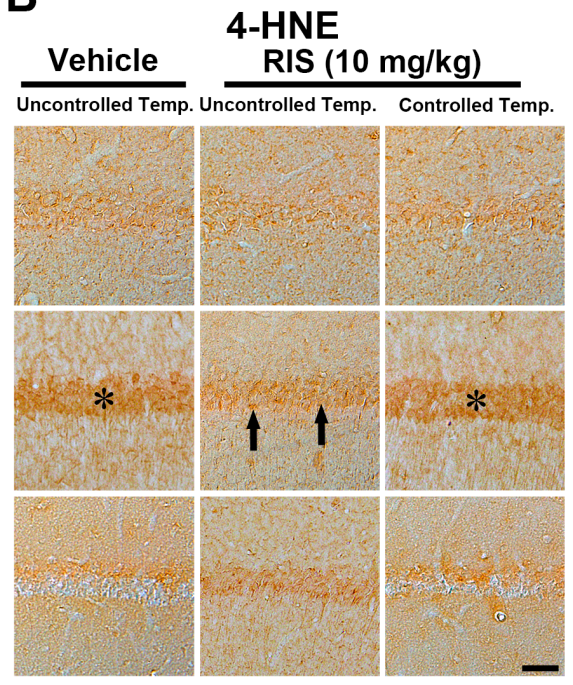

D

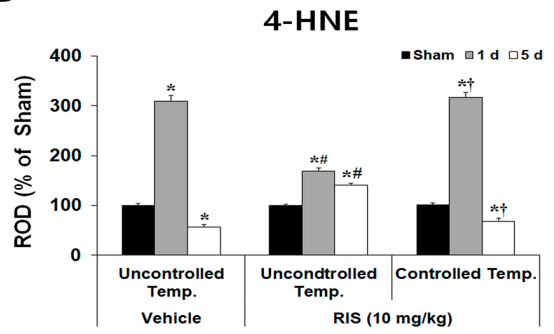

Figure 5. Effects of RIS on 8-OhdG and 4-HNE immunoreactivities after TI under UBT and CBT conditions. Representative images of immunohistochemistry for 8-OhdG (A) and 4-HNE (B) in the hippocampal CA1 after TI under UBT and CBT conditions. Under UBT condition, 8-OhdG and 4-HNE immunoreactivities in the TI + vehicle group are significantly increased in CA1 pyramidal neurons of the stratum pyramidale (SP, asterisks) in the TI + vehicle group under UBT and TI + RIS group under CBT at 1 day after TI; however, the immunoreactivities are significantly low (arrows) in the TI + RIS group under UBT. Scale bar $=50 \mu \mathrm{m}$. Note analyses of 8-OhdG (C) and 4-HNE (D) immunoreactivity in the SP. A ratio of the ROD is calibrated as \%, with the sham + vehicle group designated as $100 \%$. The bars indicate the means \pm SEM, $n=7$ /group, two-way analysis of variance (ANOVA) with a post-hoc Bonferroni's multiple comparison test $\left({ }^{*} p<0.05\right.$ vs. sham + vehicle group under UBT condition; $\# p<0.05$ vs. TI + vehicle group under UBT condition; $\uparrow p<0.05$ vs. TI + RIS group under UBT condition).

\subsubsection{Superoxide Dismutase 2 (SOD2) Level and Immunoreactivity}

SOD2 protein levels in the CA1 were differently changed according to body temperature condition (Figure 6A). SOD2 protein levels in all sham groups were not significantly different between the groups. Under UBT condition, SOD2 level of the TI + vehicle group was dramatically decreased 1 day (41\% of the sham group) after TI, and more decreased 5 days (22\% of the sham group) after TI. In the TI + RIS group, SOD2 level was not significantly changed at any time after TI. However, under CBT condition, the change pattern of SOD2 level was similar to that in the TI + vehicle group ( $54 \%$ and 
$12 \%$ of the sham group). SOD2 immunoreactivity in CA1 pyramidal neurons was differently altered according to body temperature condition (Figure 6B). In all sham groups, SOD2 immunoreactivity in CA1 pyramidal neurons was similar. Under UBT, SOD2 immunoreactivity in the TI + vehicle group was significantly reduced 1 day after TI. At 5 days after TI, SOD2 immunoreactivity was more decreased; in particular, many non-pyramidal cells showed strong SOD2 immunoreactivity. In the TI + RIS group, SOD2 immunoreactivity in CA1 pyramidal neurons was maintained at all times after TI. Under CBT condition, the change pattern of SOD2 immunoreactivity in the CA1 of the TI + RIS group was like that in the TI + vehicle group.

A

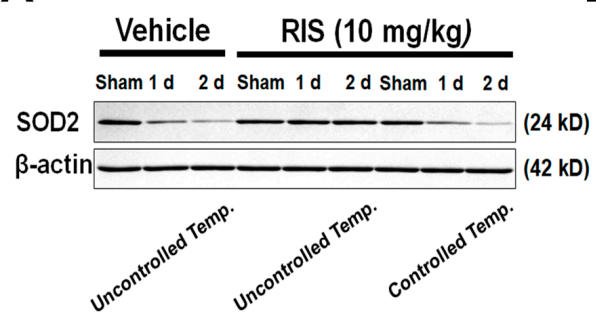

C

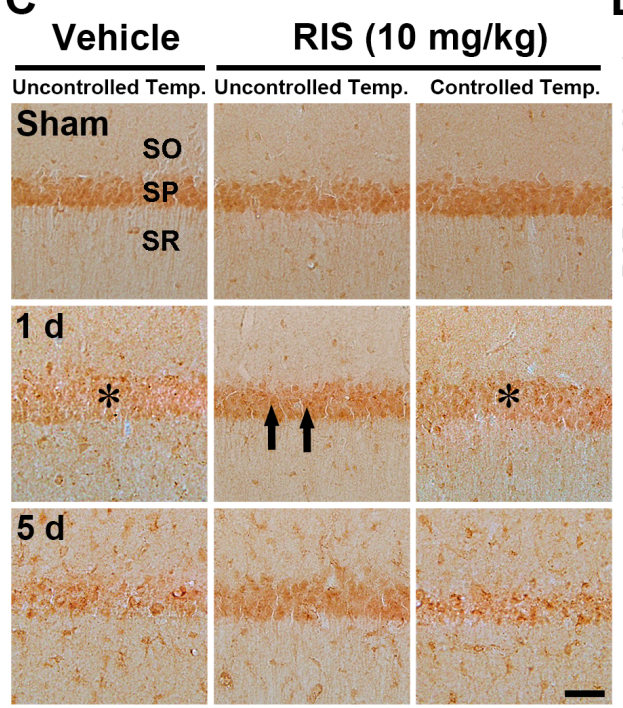

B

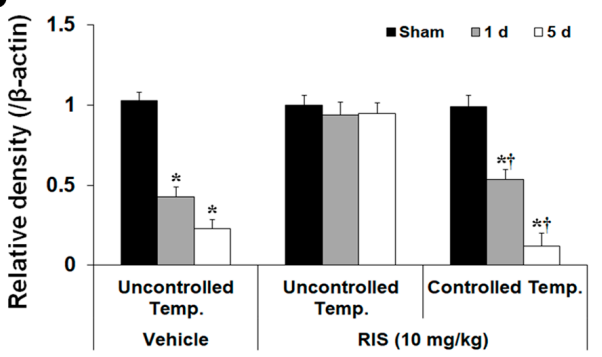

D

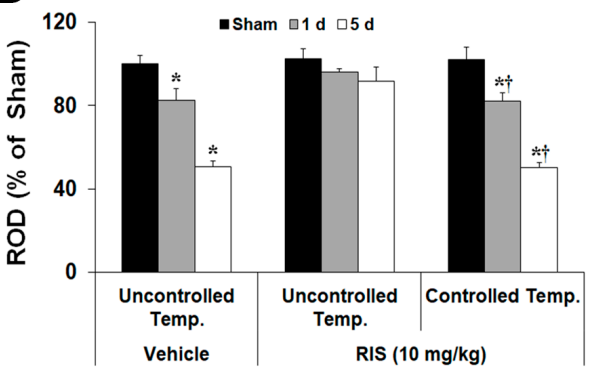

Figure 6. Effects of RIS on levels and immunoreactivity of SOD2 protein after TI under UBT and CBT conditions. (A) Western blot analysis of SOD2 protein in the hippocampus after TI under UBT and CBT conditions. Note that SOD2 levels are maintained in the TI + RIS group under UBT after TI. (B) Quantitative analysis of SOD2 protein in the hippocampus. Protein expression is normalized to $\beta$-actin. The bars indicate the means \pm SEM, $n=7 /$ group, two-way analysis of variance (ANOVA) with a post-hoc Bonferroni's multiple comparison test $\left({ }^{*} p<0.05\right.$ vs. sham + vehicle group under UBT condition; $+p<0.05$ vs. TI + RIS group under UBT condition). (C) Representative images of immunohistochemistry for SOD2 in the hippocampal CA1 after TI under UBT and CBT conditions. SOD2 immunoreactivity is significantly decreased in CA1 pyramidal neurons of the stratum pyramidale (SP, asterisks) in the TI + vehicle group under UBT and TI + RIS group under CBT at 1 day after TI; however, the immunoreactivity is maintained (arrows) in the TI + RIS group under UBT. SO, stratum oriens; SR, stratum radiatum. Scale bar $=50 \mu \mathrm{m}$. (D) Quantitative analysis of SOD2 immunoreactivity in CA1 pyramidal neurons. A ratio of ROD is calibrated as $\%$, with the sham + vehicle group designated as $100 \%$. The bars indicate the means $\pm \mathrm{SEM}, n=7 /$ group, two-way analysis of variance (ANOVA) with a post-hoc Bonferroni's multiple comparison test $\left({ }^{*} p<0.05\right.$ vs. sham + vehicle group under UBT condition; $\uparrow p<0.05 \mathrm{vs}$. TI + RIS group under UBT condition). 


\subsection{Effects of 5-HT $\mathrm{T}_{2 A^{-}}$and $\mathrm{D}_{2}$ - Receptors on RIS-Induced Hypothermia}

As shown in Figure 7, basal body temperature in all sham groups was homogenous ( 36.9 to $37.2^{\circ} \mathrm{C}$ ). Treatment with RIS $(10 \mathrm{mg} / \mathrm{kg})$ produced significant reduction $\left(31.6 \pm 0.91{ }^{\circ} \mathrm{C}\right)$ of body temperature at $60 \mathrm{~min}$ after the administration and slowly increased thereafter, and the hypothermic effect disappeared completely $240 \mathrm{~min}$ after the administration. NBOH-2C-CN hydrochloride $(5 \mathrm{mg} / \mathrm{kg})$ treatment did not significantly change body temperature, but bromocriptine mesylate $(5 \mathrm{mg} / \mathrm{kg})$ treatment showed significant decrease at $80 \mathrm{~min}$ after the administration $\left(32.9 \pm 1.64{ }^{\circ} \mathrm{C}\right)$, and the hypothermic effect disappeared $240 \mathrm{~min}$ after the administration. On the other hand, $( \pm)$-DOI hydrochloride $(5 \mathrm{mg} / \mathrm{kg})$ treatment slightly increased body temperature at $60 \mathrm{~min}$ after the administration $\left(38.6 \pm 0.93^{\circ} \mathrm{C}\right)$.

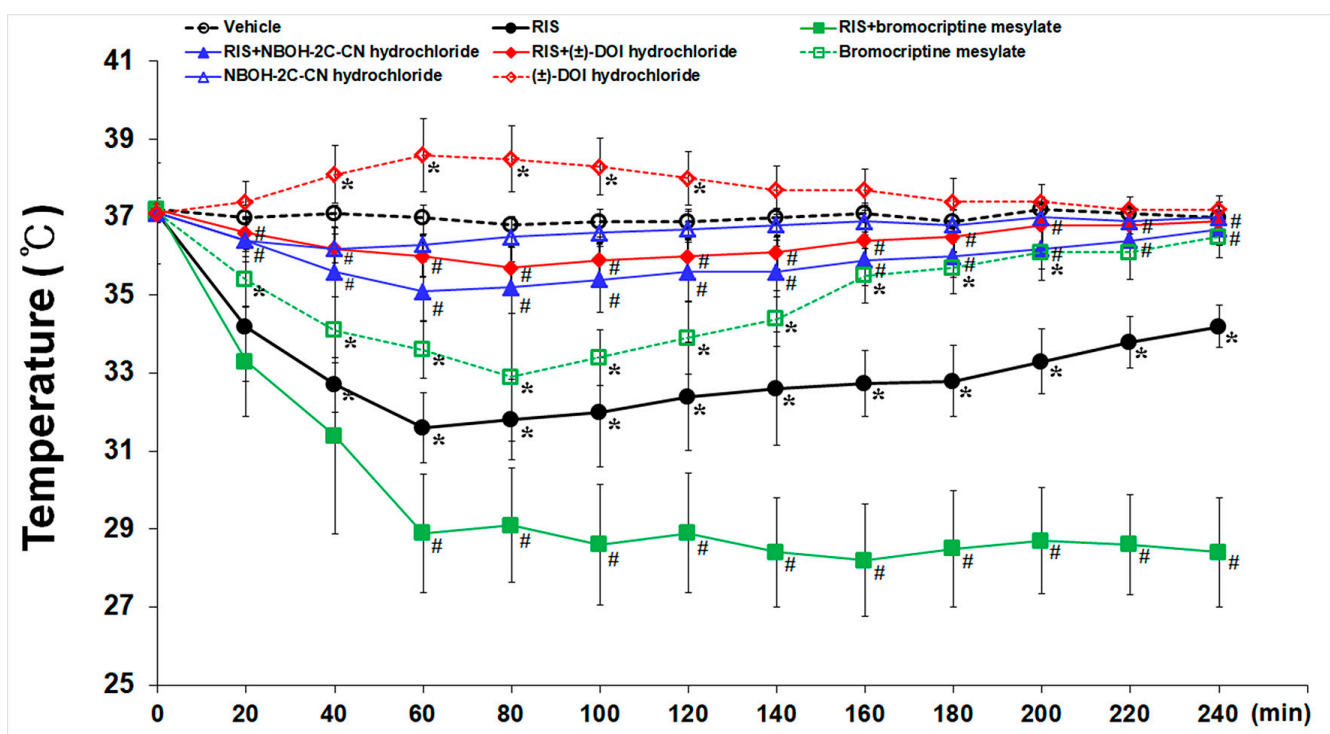

Figure 7. Effects of endogenous $5-\mathrm{HT}_{2 \mathrm{~A}}$ - and, $\mathrm{D}_{2}$-receptors on RIS-induced hypothermia. Hypothermia was defined as a reduction of at least $2{ }^{\circ} \mathrm{C}$ below baseline (normothermia). $\mathrm{NBOH}-2 \mathrm{C}-\mathrm{CN}$ hydrochloride does not alter body temperature, but bromocriptine mesylate significant decreased body temperature at $80 \mathrm{~min}$ after the administration, and $( \pm)$-DOI hydrochloride slightly increases body temperature at $60 \mathrm{~min}$ after the administration. Namely, RIS-induced hypothermia is interrupted following the administration of NBOH-2C-CN hydrochloride and ( \pm )-DOI hydrochloride. The bars indicate the means \pm SEM, $n=7$ /group, two-way analysis of variance (ANOVA) with a post-hoc Bonferroni's multiple comparison test ( $p<0.05$ vs. sham group; $\#<0.05$ vs. RIS group).

To find out roles of endogenous 5- $\mathrm{HT}_{2 \mathrm{~A}^{-}}$and $\mathrm{D}_{2}$ - receptors in RIS-induced hypothermic effect, animals were pre-treated with $\mathrm{NBOH}-2 \mathrm{C}-\mathrm{CN}$ hydrochloride, $( \pm)$-DOI hydrochloride, and bromocriptine mesylate before RIS treatment. Significant inhibition of RIS-induced hypothermia was observed in the animals treated with $\mathrm{NBOH}-2 \mathrm{C}-\mathrm{CN}$ hydrochloride and $( \pm)$-DOI hydrochloride in comparison to the animals treated with RIS alone. Unlike the $5-\mathrm{HT}_{2 \mathrm{~A}}$ receptor agonist, the hypothermic effect produced by RIS was significantly aggravated by bromocriptine mesylate. This finding might conclude that hypothermia induced by RIS could be a consequence of 5- $\mathrm{HT}_{2 \mathrm{~A}}$ receptor antagonism.

\section{Discussion}

TI selectively induces delayed neuronal death (DND) in CA1 pyramidal neurons [12]. Recently, we reported that treatment with RIS dose-dependently protected against TI-induced DND of CA1 pyramidal neurons in the gerbil hippocampus [13]. In this study, we compared neuroprotection of RIS against TI under UBT and CBT and found that $10 \mathrm{mg} / \mathrm{kg}$ RIS post-treatment significantly attenuated the DND of CA1 pyramidal neurons under UBT; however, RIS did not protect the neurons under CBT 
after TI. This finding suggests that a critical interaction between body temperature and RIS appears to permit or prevent neuroprotection.

Hypothermia is clearly established as an effective protectant against neuronal damage/death after TI [5]. In humans, hypothermia also serves as a neuroprotective procedure against cerebral hypoxia during neurosurgery and cardiovascular surgery [14,15]. Optimal protection is typically gained when hypothermia is induced as early as possible after stroke onset, with a mild-to-moderate hypothermia ( 32 to $35^{\circ} \mathrm{C}$ ) that lasts at least 1 to $2 \mathrm{~h}$ [16]. From laboratory studies, it is clear that hypothermia more consistently protects hippocampal neurons when applied soon after or even before the onset of TI $[17,18]$. Therefore, therapeutic hypothermia should be initiated as soon as possible to achieve its optimal beneficial effect. The American Heart Association cardiopulmonary resuscitation guidelines recommends that the duration of hypothermia should be at least $12 \mathrm{~h}$ [19]. Common methods for inducing therapeutic hypothermia are surface cooling and pharmacological cooling; each offers unique advantages and disadvantages [20]. In most clinical studies, therapeutic hypothermia is induced by body surface cooling. Unfortunately, the forced cooling method is slow and cumbersome, typically requiring several hours to reach target core temperature, and must be closely monitored to ensure the achievement of target temperature [21]. Furthermore, with surface cooling, precise control of core temperature is difficult. Recent methods using pharmacological agents have been suggested as a more efficient and faster way to reduce core temperature than surface cooling [22]. RIS has been reported to display hypothermia $[6,10]$. Therefore, this property makes RIS to recommend an ideal candidate for pharmacological agent as a more efficient and safer way for reducing body core temperature against ischemic insults. We, in this study, demonstrated that RIS treatment induced hypothermia within $30 \mathrm{~min}$ after post-TI and was maintained for $6 \mathrm{~h}$. Although we originally planned to use an automated hypothermia retaining system to maintain hypothermia for more than $24 \mathrm{~h}$, it was limited to $12 \mathrm{~h}$ because it was difficult to sustain due to practical problems. However, based on our study, we suggest that RIS treatment after post-TI might be easier to achieve hypothermia in the whole body and must be more practical in the clinic.

It is well known that glial cells, including astrocytes and microglia, are activated by ischemic stroke, and the activated glia has been suggested to contribute to delayed neuronal death, presumably via releasing neurotoxic substances, including reactive oxygen intermediates and pro-inflammatory cytokines [23-25]. To visualize glial cells in the hippocampal CA1 region induced by TI, we chose to use immunohistochemical staining for anti-Iba-1 (microglia) and anti-GFAP (astrocytes). We found that the activation of $\mathrm{GFAP}^{+}$and Iba- $1^{+}$cells after post-treatment with RIS was decreased significantly at 1 and 5 days after ischemia-reperfusion under UBT condition compared CBT condition. While resident glial cells exist in a ramified state, after brain injury they migrate toward the lesion, their cell body becomes ameboid-shaped, the processes shorten, and become virtually indistinguishable from macrophages. Consistent with this, in vitro, hypothermia inhibits microglia proliferation, and attenuated microglia neurotoxicity, during and critically, after exposure to hypoxia and lipopolysaccharide [26-28]. Post-ischemic hypothermia also suppressed activated microglia after cerebral ischemia in fetal sheep [29]. A recent study reported that RIS modulated morphology and functions of glial cells in C6 astroglial cells model [30]. Also, it was reported that RIS significantly inhibited the production of nitric oxide and pro-inflammatory cytokines by interferon- $\gamma$-activated microglia [31]. Therefore, in the present study, RIS-induced mild hypothermia also reduced the activation and proliferation or glial cells after ischemia-reperfusion, and thereby possibly mitigated further pathological events, leading to cell death.

Oxidative stress leads to cell death because the stress causes widespread damage of cellular components and ultimately promotes cellular death after TI injury [32,33]. Ischemic insults produce ROSs, and the interaction between ROSs and DNA produces DNA strand break and base modification, which are frequently assessed by measurement of nucleoside 8-OhdG level. Here, we compared oxidative stress between the TI + vehicle and TI + RIS group. DHE fluorescence, 8-OhdG, and 4-HNE immunoreactivity were significantly increased in CA1 pyramidal neurons of the TI + vehicle group and apparently decreased by RIS treatment under UBT after TI; the effect was abolished under CBT 
after TI. Antipsychotic drugs including RIS have a capacity to elevate antioxidants and could be used for therapy of oxidative stress that induces neuronal damage [34,35]. Antioxidants have protective effects against cerebral ischemia, suggesting that antioxidants are involved in the control of cellular damage after ischemic insults [36,37]. In this context, Altinkilic et al. [34] have demonstrated that RIS has a capacity to elevate antioxidants and is used for therapy of oxidative stress. In addition, Yan et al. [13] have reporetd that RIS treatment well maintains protein level and immunoreactivity of SOD2 in the CA1 induced by TI. In this study, level and immunoreactivity of SOD2 in the TI + RIS group was maintained under UBT, but significantly decreased under CBT. Therefore, we represent that RIS-induced hypothermia protects neurons from TI damage via maintaining endogenous antioxidants.

Alternatively, regulated hypothermia by downregulation of endogenous thermoregulation may be a better method to achieve therapeutic efficacy without severe adverse events. RIS has strong affinity for $5-\mathrm{HT}_{2 \mathrm{~A}}$ and $\mathrm{D}_{2}$ receptor with hypothermic regulatory action in the brain, and it is defined as a drop in core body temperature below $35^{\circ} \mathrm{C}[6,11]$. In this regard, we hypothesized that $5-\mathrm{HT}_{2 \mathrm{~A}}$ and receptor $\mathrm{D}_{2}$ antagonism play roles in RIS-mediated hypothermia, and found that RIS-induced hypothermia was blocked by $( \pm)$-DOI hydrochloride or NBOH-2C-CN hydrochloride treatment, suggesting that $( \pm)$-DOI hydrochloride may be involved in RIS-mediated thermoregulation. However, it was difficult to use ( \pm )-DOI hydrochloride because it produced hyperthermia in the sham + vehicle animals. $( \pm)$-DOI hydrochloride induces hyperthermic response via a $5-\mathrm{HT}_{2 \mathrm{~A}}$-mediated mechanism in rats [38,39]. Instead, we found that $\mathrm{NBOH}-2 \mathrm{C}-\mathrm{CN}$ hydrochloride did not cause hyperthermia in the vehicle animals, and RIS-induced hypothermia was partially blocked by $\mathrm{NBOH}-2 \mathrm{C}-\mathrm{CN}$ hydrochloride. Based on our findings, we suggest that blockage of $5-\mathrm{HT}_{2 \mathrm{~A}}$ receptor is essential for RIS-induced hypothermia. Bromocriptine mesylate, a potent agonist at $\mathrm{D}_{2}$ receptor, could be used to control central hyperthermia [40]. Furthermore, RIS has stronger affinity for $5-\mathrm{HT}_{2 \mathrm{~A}}$ receptor than for $\mathrm{D}_{2}$ receptor $[6,41]$. Bromocriptine mesylate induces hypothermia and reduces neuronal damage after global ischemia in rats [42]. We, in this study, found that bromocriptine mesylate significantly lowered body temperature in the TI + vehicle group and further lowered RIS-mediated hypothermia. From the reports and our data, we suggest that $\mathrm{D}_{2}$ receptor might be of minor significance since RIS-induced hypothermia did not recur with a subsequent $\mathrm{D}_{2}$ agonist treatment. Therefore, the hypothermic effect of RIS leads us to conclude that RIS-induced hypothermia might be mediated by 5- $\mathrm{HT}_{2 \mathrm{~A}}$ receptor antagonism rather than by $\mathrm{D}_{2}$ receptor antagonism.

In conclusion, RIS-induced hypothermia protected neurons from TI, and the neuroprotection might be associated with attenuation of glial activation and maintenance of antioxidants following hypothermia, showing that the hypothermia was abolished by NBOH-2C-CN hydrochloride treatment. These suggest that $5-\mathrm{HT}_{2 \mathrm{~A}}$ receptor is involved in RIS-mediated reduction of body temperature, and RIS-induced hypothermia as a post-conditioning stimulus might be given to stroke patients immediately at pick-up for hospitalization.

\section{Materials and Methods}

\subsection{Animals}

Male Mongolian gerbils (total number $=480$ ) at 6 months of age (body weight $65-75 \mathrm{~g}$ ) were obtained from the Experimental Animal Center, Kangwon National University, Chuncheon, Republic of Korea. As we described previously [43], the experimental protocol of this study was approved (no. KW-160802-1) by the Institutional Animal Care and Use Committee (IACUC) at Kangwon University. The experimental protocol adhered to guidelines from the current international laws and policies [43].

\subsection{Experimental Groups, Induction of TI, and RIS Treatment}

Experiments related with TI were two (experiment I and II). Animals in experiment I were subjected to $5 \mathrm{~min}$ TI, and body temperature of the animals was uncontrolled for $12 \mathrm{~h}$ after TI. 
Meanwhile, in experiment II, animals were subjected to $5 \mathrm{~min}$ TI, and body temperature of the animals was controlled $\left(37 \pm 0.2^{\circ} \mathrm{C}\right)$ for $12 \mathrm{~h}$ after TI. Animals (total number $\left.=432\right)$ in each experiment were divided into four groups ( $n=7$ at each point in time in each group) as follows: (1) Sham + vehicle group, which was given sham surgery for $5 \mathrm{~min}$ TI and intraperitoneally injected with vehicle; (2) TI + vehicle group, which was given 5 min TI and intraperitoneally injected with vehicle; (3) sham + RIS group, which was subjected to sham TI and intraperitoneally injected with RIS; and (4) TI + RIS group, which was subjected to $5 \mathrm{~min}$ and treated with RIS.

TI was developed as previously described [44]. In brief, the animals were anesthetized with a mixture of $2.5 \%$ isoflurane in $32 \%$ oxygen and $68 \%$ nitrous oxide. Both common carotid arteries were occluded using non-traumatic aneurysm clips (Yasargil FE 723K, Aesculap, Tuttlingen, Germany). The complete stop of blood circulation was examined in central arteries in both retinae with an ophthalmoscope (HEINE K180 ${ }^{\circledR}$, Heine Optotechnik, Herrsching, Germany). The body temperature $\left(37 \pm 0.2^{\circ} \mathrm{C}\right)$ was controlled using a thermometric blanket before and during the surgery. After $5 \mathrm{~min}$ of occlusion, the aneurysm clips were removed.

Vehicle or RIS (1, 5, and $10 \mathrm{mg} / \mathrm{kg}$; Sigma-Aldrich, St. Louis, MO, USA) was intraperitoneally administered two times (immediately and at $6 \mathrm{~h}$ ) after TI operation. Doses of RIS were selected based on a previous study [45]. RIS was dissolved in $0.3 \%$ Tween 80 in saline.

For recording temperature change in the body, rectal temperature was measured every $1 \mathrm{~h}$ after $\mathrm{TI}$, over a $12 \mathrm{~h}$ period, in a room with ambient temperature of $22 \pm 1{ }^{\circ} \mathrm{C}$. The animals in all the groups were given recovery times of 5 days after TI, because pyramidal neurons in the hippocampal CA1 area do not die until 3 days and begin to die 4 days after TI [44,46,47].

\subsection{Histological Tissue Preparation}

As previously described [44], animals ( $n=6$ at each point in time in each group) were anesthetized with pentobarbital sodium ( $30 \mathrm{mg} / \mathrm{kg}$; JW Pharmaceutical, Seoul, Korea) at the designated times and perfused transcardially with $0.1 \mathrm{M}$ phosphate-buffered saline (PBS, $\mathrm{pH} 7.4$ ) followed by $4 \%$ paraformaldehyde in $0.1 \mathrm{M}$ phosphate-buffer (PB, $\mathrm{pH}$ 7.4). Brain tissues containing hippocampi were serially sectioned into $30 \mu \mathrm{m}$ coronal sections in a cryostat (CM1900 UV, Leica, Wetzlar, Germany).

\subsection{F-J B Histofluorescence Staining}

For neuronal degeneration, F-J B (a high affinity fluorescent marker for neurodegeneration) staining was performed according to our published procedure [44]. Briefly, the sections were immersed in a solution containing $1 \%$ sodium hydroxide, transferred to a solution of $0.06 \%$ potassium permanganate, and then a solution of $0.0004 \%$ Fluoro-Jade B (Histochem, Jefferson, AR, USA). After washing, the incubated sections were placed on a slide warmer (approximately $50^{\circ} \mathrm{C}$ ) to be reacted. Finally, we examined the sections using an epifluorescent microscope (Carl Zeiss, Göttingen, Germany) with blue (450-490 nm) excitation light and a barrier filter.

\subsection{Superoxide Anion Production Detection}

For the analysis of oxidative stress, an oxidative fluorescent dye, dihydroethidium (DHE; Sigma-Aldrich), was used to evaluate in situ production of superoxide anion. Histological detection of superoxide anion was performed as described previously [48] at sham, 1 day and 5 days after TI ( $n=7$ at each time in each group). In brief, the sections were incubated with DHE $(10 \mu \mathrm{mol} / \mathrm{L})$ in PBS for $30 \mathrm{~min}$ at $37^{\circ} \mathrm{C}$ in a humidified chamber that was shielded from light. DHE was oxidized on reaction with superoxide to ethidium, which could bind to DNA in the nucleus and fluoresced red. For the detection of ethidium, the reacted sections were examined with an epifluorescent microscope (Carl Zeiss) with an excitation wavelength of 520-540 nm. The fluorescence intensity of the sections was analyzed in the stratum pyramidale at the center of the CA1 field. 


\subsection{Immunohistochemistry}

Immunohistochemistry was carried out according to our published procedure [43]. In brief, the sections were incubated with primary mouse anti-NeuN (a neuron-specific soluble nuclear antigen, diluted 1:1000, Chemicon International, Temecula, CA, USA) for neurons, mouse anti-GFAP (diluted 1:1000, Chemicon International) for astrocytes, rabbit anti-Iba-1 (1:800, Wako, Osaka, Japan) for microglia, mouse anti-4-HNE (diluted 1:1000; Alexis Biochemicals, San Diego, CA, USA) for lipid peroxidation [49], goat anti-(8-OhdG) diluted 1:500; EMD Millipore Corporation, Billerica, MA, USA) for DNA damage [50,51], and sheep anti-SOD2 (1:1000; Calbiochem, San Diego, CA, USA) for oxidative stress. The incubated sections were reacted with corresponding secondary antibodies (Vector Laboratories Inc., Burlingame, CA, USA), and developed using Vectastain ABC (Vector Laboratories Inc.). Finally, the immunoreacted sections were visualized with 3,3'-diaminobenzidine.

\subsection{Western Blotting for SOD2}

To obtain exact data for alterations in levels of SOD2 protein in the CA1 field after TI, animals ( $n=7$ at each point in time) were killed at designated times (sham, 1 day and 5 days) after TI, and tissues containing the CA1 field were used for Western blot analysis as previously described [44].

\subsection{Effects of 5-HT $T_{2 A}$ and $\mathrm{D}_{2}$ Agonists against RIS-Induced Hypothermia}

To examine the contribution of $5-\mathrm{HT}_{2 \mathrm{~A}}$ or $\mathrm{D}_{2}$ antagonism to RIS-induced hypothermia, additional gerbils ( $n=6$ /group) were intraperitoneally administered with $( \pm)$-2,5-dimethoxy-4iodoamphetamine hydrochloride $\left(( \pm)-\mathrm{DOI}, 5-\mathrm{HT}_{2 \mathrm{~A} / 2 \mathrm{C}}\right.$ agonist, $5.0 \mathrm{mg} / \mathrm{kg}$, Sigma-Aldrich), 4-[2-[(2-hydroxyphenyl)methylamino]ethyl]-2,5-dimethoxybenzonitrile (NBOH-2C-CN) hydrochloride (a selective $5-\mathrm{HT}_{2 \mathrm{~A}}$ agonist, $5.0 \mathrm{mg} / \mathrm{kg}$, Tocris Bioscience, Ellisville, $\mathrm{MO}, \mathrm{USA}$ ), or bromocriptine mesylate (a $\mathrm{D}_{2}$ agonist, $5.0 \mathrm{mg} / \mathrm{kg}$, Sigma-Aldrich) with vehicle or RIS $(10.0 \mathrm{mg} / \mathrm{kg})$, simultaneously. Rectal temperature was measured every $20 \mathrm{~min}$ after drug administration, over a $240 \mathrm{~min}$ period.

\subsection{Data Analysis}

Data analyses were performed by two or three investigators, who were blind to the experimental conditions. To analyze cell numbers and immunoreactivities, we selected six sections/animal with $120 \mu \mathrm{m}$ interval according to anatomical landmarks corresponding to AP (anteroposterior) $-1.65 \sim-3.40 \mathrm{~mm}$ of the gerbil brain atlas [52]. Firstly, we analyzed cell counts by averaging total numbers of NeuN-immunoreactive and F-J B-positive cells. Briefly, as previously described [44], images of the cells were captured in a $200 \mu \mathrm{m} \times 200 \mu \mathrm{m}$ square at the center of the stratum pyramidale of the CA1 field using an AxioM1 light microscope (Carl Zeiss, Göttingen, Germany) equipped with a digital camera (Axiocam, Carl Zeiss) connected to a PC monitor. A ratio of the count was calibrated as $\%$ of the sham + vehicle group (NeuN-immunoreactive cells) or TI + vehicle group (F-J B-positive cells) using an image analyzing system (software: Optimas 6.5, CyberMetrics, Scottsdale, AZ, USA). Secondly, quantitative analyses of GFAP, Iba-1, 8-OHdG, 4-HNE, and SOD2 immunoreactivities and DHE fluorescence intensity in the CA1 area were done as previously described [44]. In short, staining intensities of GFAP, Iba-1, 8-OHdG, 4-HNE-, and SOD2 immunoreactive structures and superoxide anion radical were evaluated on the basis of an optical density (OD), which was obtained after the transformation of the mean gray level using the formula: $\mathrm{OD}=\log (256 /$ mean gray level). Background density in the images was subtracted, and brightness and contrast were calibrated as $\%$ (relative optical density, ROD) using Adobe Photoshop version 8.0 and analyzed using NIH Image J software. A ratio of the ROD was calibrated as \%, with sham + vehicle group designated as $100 \%$.

In addition, according to our previous method [44], we scanned results of Western blot bands and carried out densitometric analyses for the quantification of the bands using Scion Image software (Scion Corp., Frederick, MD, USA). Expression rates of the target proteins were normalized through corresponding expression rates of $\beta$-actin. 


\subsection{Statistical Analysis}

The estimation of sample size was dependent on the standard deviation as in a published study by Ozkan et al. [53]. Sample size was at least seven gerbils per group with an alpha error of 0.05 and a power of $>80 \%$, calculated with power calculator (UCLA Department of Statistics, available online: http://www.stat.ubc.ca/ rollin/stats/ssize). All data are presented as mean \pm SEM. A multiple-sample comparison was applied to test the differences between groups (two-way analysis of variance (ANOVA) with a post-hoc Bonferroni's multiple comparison test). Statistical significance was considered at $p<0.05$.

Author Contributions: G.E.Y., H.-J.T., M.-H.W., and J.-C.L. were responsible for experimental design, data collection, data analysis, and manuscript writing. T.-K.L., Y.E.P., J.H.C., D.W.K., J.H.P., and J.H.A. performed the experiments. S.R., Y.-M.K., M.C.S., J.H.C., C.-H.L., I.K.H., and H.J. performed data analysis and critical comments on the whole process of this study.

Funding: This work was carried out with the support of "Cooperative Research Program for Agriculture Science and Technology Development (Project No. PJ01329401)" Rural Development Administration, Republic of Korea, and by the Bio \& Medical Technology Development Program of the NRF funded by the Korean government, MSIP (NRF-2015M3A9B6066968).

Conflicts of Interest: The authors declare no competing financial interests.

\section{References}

1. Sutherland, B.A.; Minnerup, J.; Balami, J.S.; Arba, F.; Buchan, A.M.; Kleinschnitz, C. Neuroprotection for ischaemic stroke: Translation from the bench to the bedside. Int. Stroke Soc. 2012, 7, 407-418. [CrossRef] [PubMed]

2. Busto, R.; Dietrich, W.D.; Globus, M.Y.; Ginsberg, M.D. Postischemic moderate hypothermia inhibits CA1 hippocampal ischemic neuronal injury. Neurosci. Lett. 1989, 101, 299-304. [CrossRef]

3. Nurse, S.; Corbett, D. Neuroprotection after several days of mild, drug-induced hypothermia. J. Int. Society Cereb. Blood Flow Metab. 1996, 16, 474-480. [CrossRef] [PubMed]

4. Fisher, M.; Feuerstein, G.; Howells, D.W.; Hurn, P.D.; Kent, T.A.; Savitz, S.I.; Lo, E.H. Update of the stroke therapy academic industry roundtable preclinical recommendations. Stroke 2009, 40, 2244-2250. [CrossRef] [PubMed]

5. Lyden, P.D.; Krieger, D.; Yenari, M.; Dietrich, W.D. Therapeutic hypothermia for acute stroke. Int. J. Stroke 2006, 1, 9-19. [CrossRef]

6. van Marum, R.J.; Wegewijs, M.A.; Loonen, A.J.; Beers, E. Hypothermia following antipsychotic drug use. Eur. J. Clin. Pharmacol. 2007, 63, 627-631. [CrossRef]

7. Zonnenberg, C.; Bueno-de-Mesquita, J.M.; Ramlal, D.; Blom, J.D. Hypothermia due to antipsychotic medication: A systematic review. Front. Psychiatry 2017, 8, 165. [CrossRef]

8. Schotte, A.; Janssen, P.F.; Gommeren, W.; Luyten, W.H.; Van Gompel, P.; Lesage, A.S.; De Loore, K.; Leysen, J.E. Risperidone compared with new and reference antipsychotic drugs: In vitro and in vivo receptor binding. Psychopharmacology (Berl) 1996, 124, 57-73. [CrossRef]

9. Corena-McLeod, M. Comparative pharmacology of risperidone and paliperidone. Drugs $R$ D 2015, 15, 163-174. [CrossRef]

10. Razaq, M.; Samma, M. A case of risperidone-induced hypothermia. Am. J. Ther. 2004, 11, 229-230. [CrossRef]

11. Brevik, A.; Farver, D. Atypical antipsychotic induced mild hypothermia. S D J. Med. 2003, 56, 67-70. [PubMed]

12. Colbourne, F.; Li, H.; Buchan, A.M.; Clemens, J.A. Continuing postischemic neuronal death in CA1: Influence of ischemia duration and cytoprotective doses of NBQX and SNX-111 in rats. Stroke 1999, 30, 662-668. [CrossRef] [PubMed]

13. Yan, B.C.; Park, J.H.; Ahn, J.H.; Kim, I.H.; Park, O.K.; Lee, J.C.; Yoo, K.Y.; Choi, J.H.; Lee, C.H.; Hwang, I.K.; et al. Neuroprotection of posttreatment with risperidone, an atypical antipsychotic drug, in rat and gerbil models of ischemic stroke and the maintenance of antioxidants in a gerbil model of ischemic stroke. J. Neurosci. Res. 2014, 92, 795-807. [CrossRef] [PubMed]

14. Kouchoukos, N.T.; Daily, B.B.; Wareing, T.H.; Murphy, S.F. Hypothermic circulatory arrest for cerebral protection during combined carotid and cardiac surgery in patients with bilateral carotid artery disease. Ann. Surg. 1994, 219, 699-705. [CrossRef] [PubMed] 
15. Saccani, S.; Beghi, C.; Fragnito, C.; Barboso, G.; Fesani, F. Carotid endarterectomy under hypothermic extracorporeal circulation: A method of brain protection for special patients. J. Cardiovasc. Surg. 1992, 33, 311-314.

16. Yenari, M.A.; Han, H.S. Neuroprotective mechanisms of hypothermia in brain ischaemia. Nat. Rev. Neurosci. 2012, 13, 267-278. [CrossRef] [PubMed]

17. Liu, L.; Yenari, M.A. Therapeutic hypothermia: Neuroprotective mechanisms. Front. Biosci. 2007, 12, 816-825. [CrossRef]

18. Yenari, M.; Kitagawa, K.; Lyden, P.; Perez-Pinzon, M. Metabolic downregulation: A key to successful neuroprotection? Stroke 2008, 39, 2910-2917. [CrossRef]

19. Morrison, L.J.; Deakin, C.D.; Morley, P.T.; Callaway, C.W.; Kerber, R.E.; Kronick, S.L.; Lavonas, E.J.; Link, M.S.; Neumar, R.W.; Otto, C.W.; et al. Part 8: Advanced life support: 2010 international consensus on cardiopulmonary resuscitation and emergency cardiovascular care science with treatment recommendations. Circulation 2010, 122, S345-S421. [CrossRef]

20. Faridar, A.; Bershad, E.M.; Emiru, T.; Iaizzo, P.A.; Suarez, J.I.; Divani, A.A. Therapeutic hypothermia in stroke and traumatic brain injury. Front. Neurol. 2011, 2, 80. [CrossRef]

21. Schwab, S.; Georgiadis, D.; Berrouschot, J.; Schellinger, P.D.; Graffagnino, C.; Mayer, S.A. Feasibility and safety of moderate hypothermia after massive hemispheric infarction. Stroke 2001, 32, 2033-2035. [CrossRef] [PubMed]

22. Zhang, M.; Wang, H.; Zhao, J.; Chen, C.; Leak, R.K.; Xu, Y.; Vosler, P.; Chen, J.; Gao, Y.; Zhang, F. Drug-induced hypothermia in stroke models: Does it always protect? CNS Neurol. Disord. Drug Targets 2013, 12, 371-380. [CrossRef] [PubMed]

23. Sugawara, T.; Lewen, A.; Noshita, N.; Gasche, Y.; Chan, P.H. Effects of global ischemia duration on neuronal, astroglial, oligodendroglial, and microglial reactions in the vulnerable hippocampal CA1 subregion in rats. J. Neurotrauma 2002, 19, 85-98. [CrossRef] [PubMed]

24. Stoll, G.; Jander, S.; Schroeter, M. Inflammation and glial responses in ischemic brain lesions. Prog. Neurobiol. 1998, 56, 149-171. [CrossRef]

25. Muir, K.W.; Tyrrell, P.; Sattar, N.; Warburton, E. Inflammation and ischaemic stroke. Curr. Opin. Neurol. 2007, 20, 334-342. [CrossRef]

26. Seo, J.W.; Kim, J.H.; Seo, M.; Han, H.S.; Park, J.; Suk, K. Time-dependent effects of hypothermia on microglial activation and migration. J. neuroinflammation 2012, 9, 164. [CrossRef] [PubMed]

27. Diestel, A.; Troeller, S.; Billecke, N.; Sauer, I.M.; Berger, F.; Schmitt, K.R. Mechanisms of hypothermia-induced cell protection mediated by microglial cells in vitro. Eur. J. Neurosci. 2010, 31, 779-787. [CrossRef]

28. Matsui, T.; Kida, H.; Iha, T.; Obara, T.; Nomura, S.; Fujimiya, T.; Suzuki, M. Effects of hypothermia on ex vivo microglial production of pro- and anti-inflammatory cytokines and nitric oxide in hypoxic-ischemic brain-injured mice. Folia. Neuropathol. 2014, 52, 151-158. [CrossRef]

29. George, S.; Bennet, L.; Weaver-Mikaere, L.; Fraser, M.; Bouwmans, J.; Mathai, S.; Skinner, S.J.; Gunn, A.J. White matter protection with insulin-like growth factor 1 and hypothermia is not additive after severe reversible cerebral ischemia in term fetal sheep. Dev. Neurosci. 2011, 33, 280-287. [CrossRef]

30. Quincozes-Santos, A.; Abib, R.T.; Leite, M.C.; Bobermin, D.; Bambini-Junior, V.; Goncalves, C.A.; Riesgo, R.; Gottfried, C. Effect of the atypical neuroleptic risperidone on morphology and S100B secretion in C6 astroglial lineage cells. Mol. Cell Biochem. 2008, 314, 59-63. [CrossRef]

31. Kato, R.; Sato, J.; Suzuki, H. Anesthesia for cesarean section in a parturient taking risperidone and haloperidol. Masui. Jpn. J. Anesthesiol. 2005, 54, 301-303.

32. Chan, P.H. Reactive oxygen radicals in signaling and damage in the ischemic brain. J. Cereb. Blood Flow Metab. 2001, 21, 2-14. [CrossRef] [PubMed]

33. Sugawara, T.; Chan, P.H. Reactive oxygen radicals and pathogenesis of neuronal death after cerebral ischemia. Antioxid. Redox. Signal. 2003, 5, 597-607. [CrossRef] [PubMed]

34. Altinkilic, S.; Naziroglu, M.; Uguz, A.C.; Ozcankaya, R. Fish oil and antipsychotic drug risperidone modulate oxidative stress in PC12 cell membranes through regulation of cytosolic calcium ion release and antioxidant system. J. Membr. Biol. 2010, 235, 211-218. [CrossRef] [PubMed]

35. Stojkovic, T.; Radonjic, N.V.; Velimirovic, M.; Jevtic, G.; Popovic, V.; Doknic, M.; Petronijevic, N.D. Risperidone reverses phencyclidine induced decrease in glutathione levels and alterations of antioxidant defense in rat brain. Prog. Neuropsychopharmacol. Biol. Psychiatry 2012, 39, 192-199. [CrossRef] [PubMed] 
36. Kim, G.W.; Lewen, A.; Copin, J.; Watson, B.D.; Chan, P.H. The cytosolic antioxidant, copper/zinc superoxide dismutase, attenuates blood-brain barrier disruption and oxidative cellular injury after photothrombotic cortical ischemia in mice. Neuroscience 2001, 105, 1007-1018. [CrossRef]

37. Yan, B.C.; Park, J.H.; Lee, C.H.; Yoo, K.Y.; Choi, J.H.; Lee, Y.J.; Cho, J.H.; Baek, Y.Y.; Kim, Y.M.; Won, M.H. Increases of antioxidants are related to more delayed neuronal death in the hippocampal CA1 region of the young gerbil induced by transient cerebral ischemia. Brain Res. 2011, 1425, 142-154. [CrossRef]

38. Mazzola-Pomietto, P.; Aulakh, C.S.; Wozniak, K.M.; Hill, J.L.; Murphy, D.L. Evidence that 1-(2,5-dimethoxy-4-iodophenyl)-2-aminopropane (DOI)-induced hyperthermia in rats is mediated by stimulation of 5-HT2A receptors. Psychopharmacology 1995, 117, 193-199. [CrossRef] [PubMed]

39. Salmi, P.; Ahlenius, S. Evidence for functional interactions between 5-HT1A and 5-HT2A receptors in rat thermoregulatory mechanisms. Pharmacol. Toxicol. 1998, 82, 122-127. [CrossRef]

40. Zarrindast, M.R.; Mahmoudi, M. Bromocriptine-induced hypothermia: D-2 receptor involvement. Arch. Int. de Pharmacodyn. et de Ther. 1989, 298, 38-49.

41. Perera, M.A.L.; Yogaratnam, J. De Novo delayed onset hypothermia secondary to therapeutic doses of risperidone in bipolar affective disorder. Ther. Adv. Psychopharm 2014, 4, 70-74. [CrossRef] [PubMed]

42. O'Neill, M.J.; Hicks, C.A.; Ward, M.A.; Cardwell, G.P.; Reymann, J.M.; Allain, H.; Bentue-Ferrer, D. Dopamine D2 receptor agonists protect against ischaemia-induced hippocampal neurodegeneration in global cerebral ischaemia. Eur. J. Pharmacol. 1998, 352, 37-46. [CrossRef]

43. Guide for the Care and Use of Laboratory Animals, 8th ed.; National Academies Press (US): Washington, DC, USA, 2011. Available online: https://www.ncbi.nlm.nih.gov/books/NBK54050/ (accessed on 18 September 2019).

44. Lee, J.C.; Park, J.H.; Kim, I.H.; Cho, G.S.; Ahn, J.H.; Tae, H.J.; Choi, S.Y.; Cho, J.H.; Kim, D.W.; Kwon, Y.G.; et al. Neuroprotection of ischemic preconditioning is mediated by thioredoxin 2 in the hippocampal CA1 region following a subsequent transient cerebral ischemia. Brain Pathol. 2017, 27, 276-291. [CrossRef] [PubMed]

45. Yulug, B.; Yildiz, A.; Guzel, O.; Kilic, E.; Schabitz, W.R. Risperidone attenuates brain damage after focal cerebral ischemia in vivo. Brain Res. Bull. 2006, 69, 656-659. [CrossRef] [PubMed]

46. Pulsinelli, W.A. Selective neuronal vulnerability: Morphological and molecular characteristics. Prog. brain Res. 1985, 63, 29-37. [PubMed]

47. Lee, J.C.; Cho, J.H.; Cho, G.S.; Ahn, J.H.; Park, J.H.; Kim, I.H.; Cho, J.H.; Tae, H.J.; Cheon, S.H.; Ahn, J.Y.; et al. Effect of transient cerebral ischemia on the expression of receptor for advanced glycation end products (RAGE) in the gerbil hippocampus proper. Neurochem. Res. 2014, 39, 1553-1563. [CrossRef] [PubMed]

48. Szocs, K.; Lassegue, B.; Sorescu, D.; Hilenski, L.L.; Valppu, L.; Couse, T.L.; Wilcox, J.N.; Quinn, M.T.; Lambeth, J.D.; Griendling, K.K. Upregulation of Nox-based NAD(P)H oxidases in restenosis after carotid injury. Arter. Thromb. Vasc. Biol. 2002, 22, 21-27. [CrossRef] [PubMed]

49. McKracken, E.; Graham, D.I.; Nilsen, M.; Stewart, J.; Nicoll, J.A.; Horsburgh, K. 4-Hydroxynonenal immunoreactivity is increased in human hippocampus after global ischemia. Brain Pathol. 2001, 11, 414-421. [CrossRef] [PubMed]

50. Baik, S.C.; Youn, H.S.; Chung, M.H.; Lee, W.K.; Cho, M.J.; Ko, G.H.; Park, C.K.; Kasai, H.; Rhee, K.H. Increased oxidative DNA damage in Helicobacter pylori-infected human gastric mucosa. Cancer Res. 1996, $56,1279-1282$.

51. Won, M.H.; Kang, T.C.; Jeon, G.S.; Lee, J.C.; Kim, D.Y.; Choi, E.M.; Lee, K.H.; Choi, C.D.; Chung, M.H.; Cho, S.S. Immunohistochemical detection of oxidative DNA damage induced by ischemia-reperfusion insults in gerbil hippocampus in vivo. Brain Res. 1999, 836, 70-78. [CrossRef]

52. Radtke-Schuller, S.; Schuller, G.; Angenstein, F.; Grosser, O.S.; Goldschmidt, J.; Budinger, E. Brain atlas of the Mongolian gerbil (Meriones unguiculatus) in CT/MRI-aided stereotaxic coordinates. Brain Struct. Funct. 2016, 221, 1-272. [CrossRef] [PubMed]

53. Ozkan, A.; Sen, H.M.; Sehitoglu, I.; Alacam, H.; Guven, M.; Aras, A.B.; Akman, T.; Silan, C.; Cosar, M.; Karaman, H.I. Neuroprotective effect of humic Acid on focal cerebral ischemia injury: An experimental study in rats. Inflammation 2015, 38, 32-39. [CrossRef] [PubMed]

(C) 2019 by the authors. Licensee MDPI, Basel, Switzerland. This article is an open access article distributed under the terms and conditions of the Creative Commons Attribution (CC BY) license (http://creativecommons.org/licenses/by/4.0/). 